\title{
GC-MS Modified Quechers Method for Multiresidue Pesticide Determination in Red Wine
}

\author{
Maja Pelajić, ${ }^{1}$ Izidor Pelajić, ${ }^{2}$ Dragana Mutavdžić Pavlović, ${ }^{3}$ Dubravka Vitali Čepo ${ }^{4, *}$
}

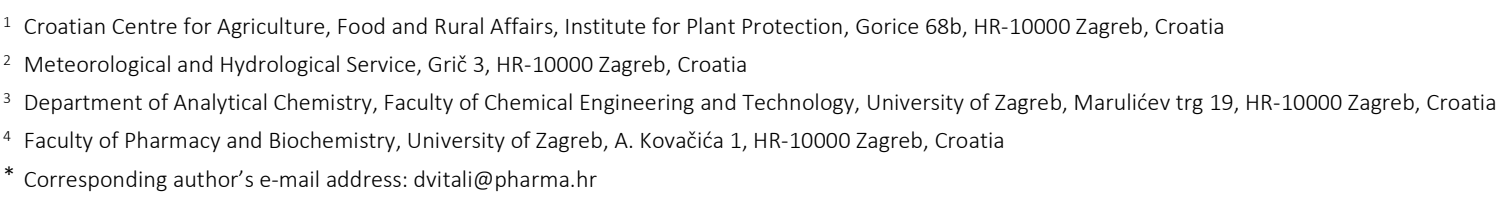

RECEIVED: July 18, 2019 * REVISED: October 2, 2019 * ACCEPTED: October 3, 2019

\begin{abstract}
This work reports a new selective and accurate multiresidue procedure for determination of 25 pesticides in red wine by GC-MS. Proposed procedure uses an original approach in sample preparation technique based on QuEChERS theory. Main focus of method development was modification of salts thus increasing ionic strength of solution which improved pesticides partitioning and extraction efficiency. LOQs were in the range $0.01-250 \mu \mathrm{g} \mathrm{L}^{-1}$ with $56 \%$ of target pesticides below or equal to $10 \mu \mathrm{g} \mathrm{L} \mathrm{L}^{-1}$. RSD for most pesticides was $<20 \%$ and recoveries were in the range $70-120 \%$. Matrix effect was found to be high for five pesticides confirming sample preparation procedure to be efficient. The proposed procedure was applied to 12 wine samples of different variety with determination of $40 \%$ of target pesticides. Developed GCMS methodology provides novel, selective and accurate approach for determination of 25 pesticide residues in red wine.
\end{abstract}

Keywords: multiresidue method, GC-MS, pesticide residues, red wine, QuEChERS.

\section{INTRODUCTION}

$\mathbf{N}$ OWADAYS, there is an essential need for pesticide residue analysis in food and environmental samples. Maximum levels for contaminants in food are decreasing, which has resulted in a growing need for more sensitive and reliable detection methodology. Such methods should not be oriented toward single pesticide analysis but toward development of multiresidue methods for simultaneous detection of a wide variety of pesticides. Furthermore, trace analysis of pesticides requires efficient sample preparation. [1] Determination techniques based on chromatographic separations are continuously improving; the use of mass spectrometry has enabled detection of analyte by the selection of ions of interest, reducing in this way the interferences. Matrix effects can have a great impact on detection systems; for instance detector noise, analyte response or ionization efficiency, which is directly related to the limits of detection and quantification. ${ }^{[2]}$

Nevertheless, sample treatment is still one of the key element of analytical procedure. ${ }^{[3]}$ The choice of extraction technique depends on differences in physicochemical properties of analyte and complexity of the matrix. Sample preparation generally includes homogenization, extraction, clean up and concentration. Traditional sample preparation is time-consuming, expensive and in most cases includes the use of toxic organic solvents in large quantities. Compared to the classical liquid-liquid extraction (LLE), solid phase extraction (SPE) provides several advantages such as lower consumption of organic solvents, reduced time of analysis and efficient removal of matrix interferences, providing, in such way, lower limits of detection and quantification. ${ }^{[4-8]}$

A different sample preparation methodology with the acronym QuEChERS (Quick, Easy, Cheap, Effective, Rugged and Safe) has been first introduced by Wong and co-workers, ${ }^{[9]}$ providing reliable results and reducing the number of sample preparation steps. Methodology has been successfully applied on food and vegetables matrices, ensuring selectivity and reproducibility with satisfactory recoveries of wide range of pesticides. ${ }^{[2-7]}$ It is a method of choice which reduces the sample size and the quantity of 
laboratory glassware by combining several preparation steps. The QuEChERS methodology simplifies the analyte extraction and sample clean up, in principle without affecting the magnitude of analyte recoveries. Over the years methodology has been modified and enhanced depending on applied matrix.

Due to the high complexity of the matrix, analysis of wine is a challenge. In most cases, solid phase extraction has been method of choice for determination of pesticides residues in wine. ${ }^{[8-12]}$ In last decade, QuEChERS methodology has been extended to various types of matrices. However, according to the literature QuEChERS has been poorly researched on wine samples. ${ }^{[13]}$

In this study a new multiresidue method for determination of 25 pesticides in wine samples by gas chromatography-mass spectrometry (GC-MS) is introduced. The focus of the method development was set on QuEChERS methodology, originally not proposed for wine samples. ${ }^{[9]}$ With the aim of expanding a current knowledge about matrix influence, red wine had been chosen for method development. Influence of the wine matrix on identification and quantification of 25 pesticides was investigated by evaluation of extraction efficiency of the proposed methodology. Relevant statistical analysis of data obtained during validation was performed. For confirmation, proposed methodology was applied on real wine samples.

\section{EXPERIMENTAL}

\section{Sample Collection}

The wine varieties under study were Frankovka, Zweigelt, Plavac and Pinot noir, selected as the most widely consumed red wine varieties in Coatia. They were collected from three major wine-growing regions of Croatia: eastern contitnental Croatia, western continental Croatia and coastal Croatia. All analyzed samples were bottled after 1 year of aging in stainless steel tanks. Prior to the analyses, bottles were opened and aliquots containing $50 \mathrm{~mL}$ of wine samples were stored in plastic containers at $4{ }^{\circ} \mathrm{C}$ until analysis. Pesticide analyzes were conducted within the next 6 months.

\section{Reagents and Chemicals}

Pesticides included in this investigation include active compounds that were authorized for use in grapes in Croatia at the time of wine sample collection. 25 certified pesticide standards used in this work were purchased from SigmaAldrich (Germany) and Dr. Ehrenstorfer GmbH (Germany). Acetonitrile (HPLC grade) was purchased from J. T. Baker (Netherlands) and toluene from Sigma-Aldrich (Germany). Magnesium sulphate anhydrous was purchased from Acros
Organics (USA), sodium chloride from Carlo Erba Reagents (Italy), sodium acetate and trisodium citrate dihydrate from Fischer Scientific (UK). Primary secondary amine (PSA) was purchased from Agilent (USA). Tetraphenylethylene (TEP) was used as an internal standard (Sigma-Aldrich, Germany). Cellulose acetate membrane filters $(0.22 \mu \mathrm{m}$ pore size) were purchased form Millipore (USA).

Individual standard pesticide stock solutions were prepared in acetone in concentration range $500-3125 \mathrm{mg} \mathrm{L}^{-1}$. The standard working mixtures were prepared by appropriate dilution with acetone. Red wine without presence of target pesticide (Babić) was used for method development and for preparation of matrix-matched standard solutions. The internal standard solution was prepared in toluene at concentration $100 \mu \mathrm{g} \mathrm{mL}-1$. Standard and stock solutions were stored at $4{ }^{\circ} \mathrm{C}$ in the dark.

\section{Sample Preparation}

Red wine was filtered through cellulose acetate membrane filters and processed within $48 \mathrm{~h} .10 \mathrm{~mL}$ of wine was transferred into a $50 \mathrm{~mL}$ centrifuge tube. Then, $10 \mathrm{~mL}$ of acetonitrile was added to the wine sample and vortexed (IKA Vortex Genius 3, Germany) for $1 \mathrm{~min}$. Afterwards, $4 \mathrm{~g}$ of magnesium sulphate anhydrous, $1.5 \mathrm{~g}$ of sodium chloride, $2 \mathrm{~g}$ of sodium acetate and $2 \mathrm{~g}$ of trisodium citrate dihydrate were added to the sample. The centrifuge tube was mixed by hand, vortexed in turn for $10 \mathrm{~min}$ and centrifuged (Universal 320, Hettich, Germany) at $4000 \mathrm{rpm}$ for $15 \mathrm{~min} .8 \mathrm{~mL}$ of supernatant was transferred into a $15 \mathrm{~mL}$ centrifuge tube containing $400 \mathrm{mg}$ of PSA and $1.2 \mathrm{~g}$ of magnesium sulphate anhydrous. The centrifuge tube was vortexed for $3 \mathrm{~min}$ and centrifuged at $4000 \mathrm{rpm}$ for $15 \mathrm{~min}$. The aliquot was evaporated to dryness by vacuum rotary evaporator (EZ-2 Plus, Genevac, UK) and diluted with $1 \mathrm{~mL}$ of acetone before GC-MS analysis.

\section{Instrumentation Analysis}

The analysis was performed on $6890 \mathrm{~N}$ gas chromatograph with the mass spectrometer 5975 inert and 7863B autosampler (Agilent, USA). A HP-5MS capillary column (30 $\mathrm{m} \times 0.25 \mathrm{~mm}$, i.d. $\times 0.25 \mu \mathrm{m}$ film thickness), (Agilent $\mathrm{J} \& \mathrm{~W}$ Scientific Products, USA) was used for pesticide separation with helium as carrier gas (purity 6.0, Messer, Germany) and flow rate of $1.0 \mathrm{~mL} \mathrm{~min}{ }^{-1} .5 \mu \mathrm{L}$ of sample was injected at $250{ }^{\circ} \mathrm{C}$ in pulsed splitless mode. The following oven temperature program was conducted: initial temperature $120^{\circ} \mathrm{C}$, held for $1 \mathrm{~min} ; 30^{\circ} \mathrm{C}$ per minute to $190^{\circ} \mathrm{C}$, held for $1 \mathrm{~min} ; 5^{\circ} \mathrm{C}$ per minute to $205^{\circ} \mathrm{C}$, held for $1 \mathrm{~min} ; 2^{\circ} \mathrm{C}$ per minute to $217{ }^{\circ} \mathrm{C}$, with no held; $6{ }^{\circ} \mathrm{C}$ per minute to $232{ }^{\circ} \mathrm{C}$, held for $1 \mathrm{~min} ; 10{ }^{\circ} \mathrm{C}$ per minute to $240{ }^{\circ} \mathrm{C}$, with no held; $40^{\circ} \mathrm{C}$ per minute to $320^{\circ} \mathrm{C}$, held for $3 \mathrm{~min}$. The temperature of ion source was $230^{\circ} \mathrm{C}$, transfer line temperature was 280 ${ }^{\circ} \mathrm{C}$ and MS quad temperature was $150{ }^{\circ} \mathrm{C}$. The electron 
impact ionization was set to $70 \mathrm{eV}$. Total run time was $23.63 \mathrm{~min}$ with solvent delay $4.5 \mathrm{~min}$. The analysis was performed in single ion monitoring (SIM) mode. Pesticides were identified according to their retention times, quantification ion (target ion) and three qualifier ions.

\section{Validation and Matrix Effect}

For validation studies red wine (Babić) with no traces of target pesticides was used as blank. Absolute recoveries were calculated as the difference between concentrations measured in spiked sample and non spiked sample, divided by theoretical concentration added to the sample, multiplied by 100 . The recovery studies, expressed as method trueness and precision, were conducted at two concentration levels, $2 \times \mathrm{LOQ}$ and $10 \times \mathrm{LOQ}$. For the reproducibility determination at each concentration level five replicates were evaluated per day for five days. Linearity was evaluated in the concentration range LOQ-2500 $\mathrm{g} \mathrm{L}^{-1}$. The measure of matrix effect was estimated from the slopes ratio of the pesticides calibration curves in matrix and in solvent.

\section{RESULTS AND DISCUSSION}

\section{Optimization of Extraction Procedure}

Considering a wide range of pesticides physicochemical properties and their different chemical classes, extraction protocol often includes multistep procedure with additional sample clean up and usage of a large amount of chemicals. The QuEChERS method includes simple extraction with acetonitrile, partitioning with magnesium sulphate and other salts following additional clean up step using dispersive solid phase extraction (dSPE). As mentioned before, the proposed method was successfully applied on food and vegetables matrices. ${ }^{[9]}$

The main goal of this study was to develop and optimize new multiresidue method for determination of pesticides in wine based on QuEChERS methodology. ${ }^{[5,13,14]}$ Original QuEChES methodology was applied ( $6 \mathrm{~g}$ of magnesium sulphate and $1.5 \mathrm{~g}$ of sodium acetate) but did not give satisfactory recoveries, < $20 \%$ (Figure 1). An important factor that could affect the extraction efficiency is high ethanol content present in wine, ranging between $11-14 \% .^{[5]}$ In accordance with QuEChERS methodology, dilution with water did not improve extraction efficiency. These results are consistent with available literature reporting no improvement in recoveries for diluted samples with high water content ( $>80 \%$ ). ${ }^{[15]}$

One of the key elements in QuEChERS theory is salting out effect with magnesium sulphate and adjusting the polarity of organic phase. ${ }^{[3,16]}$ Addition of salts induces phase separation and thus transition of analyte between two phases. It was observed that changing the amount of magnesium sulphate (2-8 g) improved recoveries, although not sufficiently. Addition of sodium chloride and trisodium citrate dihydrate to magnesium sulphate and sodium acetate had significant influence on recovery improvement. The purpose of sodium chloride is to increase ionic strength of the water, and thereby increasing its polarity. ${ }^{[16]}$ The amount of sodium chloride is critical because the excess of sodium chloride reduces partitioning of polar pesticides to organic phase. Recoveries between 60-120 \% were obtained with $1.5 \mathrm{~g}$ of sodium chloride, with exceptions for zoxamide (10\%) and captan (50\%). With higher amount of sodium chloride ( $3 \mathrm{~g}$ and $4 \mathrm{~g}$ ) recoveries were lower for the most pesticides (< $70 \%$ ). An extended QuEChERS methodology includes the use of disodium citrate sesquihydrate along with magnesium sulphate, sodium chloride and sodium citrate.[21] However, addition of sodium citrate monobasic and disodium citrate sesquihydrate did not influence pesticide extraction.

It was observed that recoveries fluctuated significantly with changes in the amount of sodium acetate and trisodium citrate dihydrate. This could be related to $\mathrm{pH}$ of the sample. According to the original methodology, $\mathrm{pH}$ should be between 5 and 5.5. ${ }^{[9]}$ However, $\mathrm{pH}$ at which extraction is performed can influence the coextraction of matrix compounds. Lower and higher $\mathrm{pH}$ values result in inefficient pesticide partitioning between two layers, depending on pesticide polarity. With addition of citrate salt and sodium acetate $\mathrm{pH}$ of the sample can be controlled. The acceptable recoveries (80-120 \%) were achieved with $2 \mathrm{~g}$ of sodium acetate and $2 \mathrm{~g}$ of trisodium citrate dihydrate for all pesticides with exceptions for zoxamide (30\%) and captan (55\%). pH of the sample was 5.5 as in original methodology. The lower amount of these salts $(1 \mathrm{~g})$ resulted in lower recoveries $(<80 \%)$. Addition of different amounts of salt resulted in variation of the red colour of the organic phase what could indicate $\mathrm{pH}$ change.

Above mentioned reddish colour indicates the presence of anthocyanins. ${ }^{[6,22]}$ At natural $\mathrm{pH}$ of wine (3-3.5) anthocyanins are present in ionized form. Due to their reactivity, anthocyanins are expected to be extracted with pesticide thus pronouncing the matrix effect. With $\mathrm{pH}$ increasing anthocyanins start to deprotonate. The result of these reactions is colour change from red to bluish red.

Sample cleanup is essential for matrix interferences removal. The obtained results showed extremely low recoveries $(<20 \%)$ without sample clean up. Due to its high ion exchange ability, PSA is the most popular solid phase extraction (SPE) sorbent for pesticide multiresidue analysis with successful matrix interference removal. ${ }^{[23]}$ Considering that wine is water based sample without presence of fat, carotenoids or chlorophyll, dispersive SPE is performed using PSA according to the original methodology. The effect 
of different amounts of PSA was investigated $(200 \mathrm{mg}$, $400 \mathrm{mg}$ and $600 \mathrm{mg}$ ). At higher amount of PSA (600 mg) recoveries were lower compared to medium amount (400 mg). This could be related to immediate $\mathrm{pH}$ change to 8 after the contact with PS. ${ }^{[19]}$ At higher $\mathrm{pH}$ many pesticides become unstable. The degradation of captan and chlorothalonil can occur at higher amount of PSA which has been confirmed by recovery loss and chromatogram appearances. At $200 \mathrm{mg}$ of PSA recoveries were equal or lower to those obtained at $600 \mathrm{mg}$ of PSA. Compared to colourless extracts obtained with $400 \mathrm{mg}$ and $600 \mathrm{mg}$ of PSA, extraction with $200 \mathrm{mg}$ of PSA yielded reddish extracts indicating inefficient anthocyanins removal and causing low pesticide recoveries. Based on obtained results $400 \mathrm{mg}$ of PSA was chosen as the amount of sorbent needed for efficient matrix interference removal. For the removal of excess water and additional improvement of extraction, magnesium sulphate has been added to PSA. It has been noted that the amount of magnesium sulphate did not have significant influence at this step of sample preparation. Therefore, $1.2 \mathrm{~g}$ of magnesium sulphate was chosen according to the original methodology.

Our results indicate that original QuEChERS methodology is not applicable for determination of pesticide residues in red wine. Obtained recoveries were not acceptable without further development and optimization of original methodology. For pesticide extraction $\mathrm{pH}$ should be 55.5. ${ }^{[9]}$ However, pesticide extraction is inefficient without additional combination of salts which was not proposed by original methodology.

\section{Method Validation}

Validation of the proposed analytical methodology was performed according to the guidelines for pesticides residues monitoring ${ }^{[17]}$ for which linearity, selectivity, limit of detection (LOD) and quantification (LOQ), precision and accuracy were determined. In order to reduce established matrix interference described in details in subsection 3.4., calibration solutions were prepared in matrix. Analytical

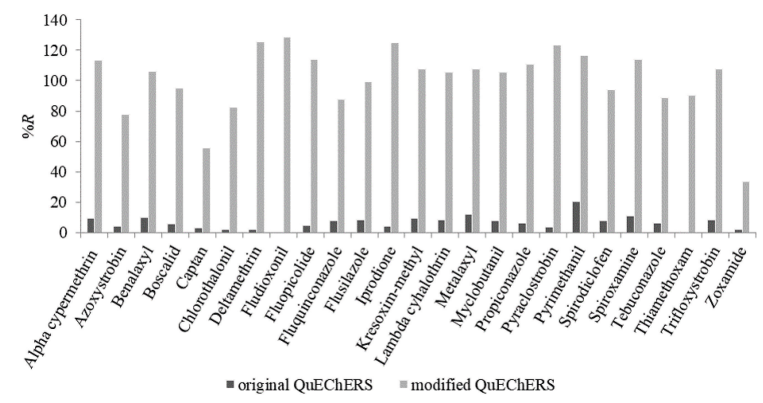

Figure 1. Comparison of original and modified QuEChERS methodology. procedure was developed and validated in red wine with no presence of target pesticides.

The determination of selectivity was based on comparison of chromatograms of blank red wine and pesticide standard prepared in solvent. No interference on target peaks was observed.

$\angle O D$ and $\angle O Q$ were in the range $0.01-50 \mu \mathrm{g} \mathrm{L}^{-1}$ and $0.25-250 \mu \mathrm{g} \mathrm{L}^{-1}$ respectively. Values were determined based on signal-to-noise ratio $(\mathrm{S} / \mathrm{N})$, three times ratio for $L O D$ and ten times ratio for $L O Q$, estimated from blank wine sample (Table 1).

Linearity was determined by calculating determination coefficient $\left(R^{2}\right)$ of the linear regression equations based on minimum five point calibration curve. Concentration ranges and determination coefficient are shown in Table 1. Determination coefficient for all pesticide was $>0.99$.

Recovery studies were performed at two concentration levels; $2 \times$ LOQ and $10 \times$ LOQ. Precision and accuracy were determined based on five replicates on each level for five consecutive days. At lower concentration level the intra-day recoveries were within acceptable range 70-120\% with the lowest recovery for deltamethrin and spirodiclofen $(77 \%)$ and the highest for chlorothalonil (120\%). For all pesticides relative standard deviations (RSD) at given level were $<20 \%$ with highest value for boscalid and spiroxamine (7\%). At higher concentration level for 20 pesticide recoveries were between $70-120 \%$ with exception for spirodiclofen $(67 \%)$. RSD values for these pesticides were acceptable (<20\%) with exception for fludioxonil (24\%). Recoveries were significantly lower for 5 pesticides: azoxystrobin (55\%), pyraclostrobin (43\%), boscalid (60\%), zoxamide (51 \%) and captan (40\%) in comparison with lower level where recoveries were $115 \%, 120 \%$, $94 \%, 101$ $\%$ and $89 \%$ respectively. RSD values for these 5 pesticides were similar to those at lower level. For zoxamide RSD value were slightly higher (16\%) in comparison with lower level (3\%). Results obtained for these 5 pesticides indicate the presence of matrix which has been described in subsection 3.4. In addition, recovery loss is expected for these pesticides as mentioned in subsection 3.1. These pesticides are base sensitive so they start to degrade in contact with PSA where $\mathrm{pH}$ changes to 8 , especially at higher concentrations. The average recoveries were calculated based on the results collected during five consecutive days. Recoveries at both concentration levels were in the range $70-120 \%$ with RSD $<20 \%$. Exceptions were azoxystrobin $(57 \%)$, pyraclostrobin (42\%), boscalid (55\%), zoxamide (49\%) and cap$\tan (46 \%)$ at higher concentration level. For fludioxonil average RSD was $18 \%$ which is lower than intra-day value (24\%) in comparison with zoxamide whose intra-day RSD were higher ( $25 \%$ ) than inter-day value (16\%). The precision and accuracy data are demonstrated in the Table 1. 
Table 1. LOD, LOQ, linearity, accuracy and precision at two concentration levels ( $2 \times$ LOQ and $10 \times L O Q)$. Recovery $(\% R)$ and relative standard deviation (RSD\%).

\begin{tabular}{|c|c|c|c|c|c|c|c|c|}
\hline \multirow{3}{*}{ Compound } & \multirow{3}{*}{$\mathrm{LOD} / \mu \mathrm{g} \mathrm{L^{-1 }}$} & \multirow{3}{*}{$\mathrm{LOQ} / \mu \mathrm{g} \mathrm{L^{-1 }}$} & \multirow{2}{*}{\multicolumn{2}{|c|}{ Linearity }} & \multirow{2}{*}{\multicolumn{2}{|c|}{$\frac{\text { Repeatibility }^{(a)}}{\% R(\text { RSD / \%) }}$}} & \multirow{2}{*}{\multicolumn{2}{|c|}{$\frac{\text { Reproducibitily }^{(\mathrm{b})}}{\% R(\mathrm{RSD} / \%)}$}} \\
\hline & & & & & & & & \\
\hline & & & $R^{2}$ & Range / $\mu g \mathrm{~L}^{-1}$ & $2 \times \operatorname{LOQ}$ & $10 \times \mathrm{LOQ}$ & $2 \times \operatorname{LOQ}$ & $10 \times \mathrm{LOQ}$ \\
\hline Azoxystrobin & 50 & 250 & 0.9970 & LOQ-2500 & $114.7(2)$ & $55.3(6)$ & $111.2(4$ & $56.5(11)$ \\
\hline Benalaxyl & 0.01 & 0.25 & 0.9923 & LOQ-1500 & $82.1(3)$ & $79.4(6)$ & $77.0(4)$ & $96.6(6)$ \\
\hline Boscalid & 10 & 50 & 0.9917 & LOQ-1000 & $94.1(7)$ & $60.1(6)$ & $94.7(4)$ & $54.9(5)$ \\
\hline Captan & 2.5 & 50 & 0.9917 & LOQ-2500 & $88.9(1)$ & $40.5(3)$ & $82.9(3)$ & $45.9(4)$ \\
\hline Chlorothalonil & 1 & 10 & 0.9941 & LOQ-2500 & $120.1(3)$ & $93.6(3)$ & $117.0(7)$ & $104.2(4)$ \\
\hline Lambda cyhalothrin & 0.025 & 5 & 0.9954 & LOQ-1500 & $81.6(2)$ & $74.7(4)$ & $75.8(3)$ & $79.4(5)$ \\
\hline Alpha cypemethrin & 0.5 & 5 & 0.9955 & LOQ-1500 & $80.3(4)$ & $73.2(2)$ & $78.5(4)$ & $83.5(4)$ \\
\hline Deltamethrin & 5 & 50 & 0.9921 & LOQ-2500 & $76.7(2)$ & $75.5(3)$ & $74.4(3)$ & $87.3(3)$ \\
\hline Fludioxonil & 50 & 250 & 0.9916 & LOQ-2500 & $109.9(3)$ & $73.4(24)$ & $103.9(3)$ & $74.4(18)$ \\
\hline Fluopicolide & 0.25 & 5 & 0.9931 & LOQ-1500 & $110.0(3)$ & $81.5(4)$ & $109.4(3)$ & $85.5(4)$ \\
\hline Fluquinconazole & 0.01 & 5 & 0.9903 & LOQ-1000 & $83.1(1)$ & $70.0(4)$ & $75.0(3)$ & $70.5(4)$ \\
\hline Flusilazole & 0.5 & 5 & 0.9928 & LOQ-1500 & $117.6(2)$ & $76.6(9)$ & $111.2(3)$ & $79.0(5)$ \\
\hline Iprodione & 0.01 & 1 & 0.9979 & LOQ-1500 & $93.0(2)$ & $106.2(3)$ & $94.7(4)$ & $118.0(4)$ \\
\hline Kresoxim methyl & 0.5 & 5 & 0.9919 & LOQ-1500 & $102.0(2)$ & $81.1(2)$ & $95.0(3)$ & $90.5(3)$ \\
\hline Metalaxyl & 0.01 & 10 & 0.9993 & LOQ-400 & $119.3(0.4)$ & $96.9(2)$ & $112.0(3)$ & $105.4(3)$ \\
\hline Myclobutanil & 2.5 & 10 & 0.9928 & LOQ-1500 & $119.2(5)$ & $90.2(2)$ & $121.1(4)$ & $102.2(4)$ \\
\hline Propiconazole & 2.5 & 5 & 0.9984 & LOQ-400 & $99.5(1)$ & $100.1(5)$ & $98.4(3)$ & $90.6(6)$ \\
\hline Pyraclostrobin & 50 & 250 & 0.9944 & LOQ-2500 & $120.0(1)$ & $43.5(7)$ & $118.9(3)$ & $41.5(10)$ \\
\hline Pyrimethanil & 0.01 & 5 & 0.9923 & LOQ-1500 & $104.9(1)$ & $116.1(2)$ & $114.4(3)$ & $121.1(4)$ \\
\hline Spirodiclofen & 5 & 50 & 0.9921 & LOQ-2500 & $76.7(3)$ & $67.1(2)$ & $78.1(3)$ & $69.2(4)$ \\
\hline Spiroxamine & 10 & 50 & 0.9906 & LOQ-1500 & $110.7(7)$ & $91.3(2)$ & $112.5(4)$ & $102.3(3)$ \\
\hline Tebuconazole & 25 & 50 & 0.9981 & LOQ-1000 & $115.4(2)$ & $87.3(22)$ & $107.9(3)$ & $81.1(8)$ \\
\hline Thiamethoxam & 25 & 50 & 0.9953 & LOQ-2000 & $113.4(2)$ & $81.9(5)$ & $107.8(3)$ & $86.3(5)$ \\
\hline Trifloxystrobin & 0.025 & 5 & 0.9912 & LOQ-1500 & $117.9(4)$ & $71.3(3)$ & $114.5(3)$ & $81.7(3)$ \\
\hline Zoxamide & 5 & 50 & 0.9901 & LOQ-1500 & $100.8(3)$ & $50.5(16)$ & $88.1(4)$ & $49.3(25)$ \\
\hline
\end{tabular}

\section{Measurement Uncertainty}

Measurement uncertainty was determined using validation data obtained from five replicates on two concentration levels $(2 \times \mathrm{LOQ}$ and $10 \times \mathrm{LOQ})$ for five consecutive days. As uncertainty $(u)$ of the measurement $(Y)$ can be expressed as: $u(Y)^{2}=s^{2} w_{L}+u(\delta)^{2}+s^{2}$ other, where $s_{W L}$ stands for withinlaboratory standard deviation, $u(\delta)$ is uncertainty associated with the bias of the method and $s_{\text {other }}$ stands for all other contribution to overall uncertainty. ${ }^{[11]}$ Since the major contributions to uncertainty are from withinlaboratory standard deviation and uncertainty of the method, overall uncertainty can be expressed in simplified form as $u(Y)^{2}=s^{2} w L+u(\delta)^{2}$. It is possible to estimate bias uncertainty of the method $u(\delta)$ and within-laboratory variance from within day $s^{2}$ WD and between-days $s^{2}$ BD variances, thus analysis of variance procedure (ANOVA) was conducted over validation dataset. Assuming that all measurements for each pesticide on each day on both concentration levels are independent, assuming normality 
of the measurements and considering that all variances were similar, ANOVA procedure was used to retrieve within-day $s^{2}$ WD and between-days $s^{2}$ BD variances. Uncertainty of the measurements $u(Y)$ were afterword expanded into expanded uncertainty $U(Y)$ with coverage factor $k=2$ to account for $95 \%$ confidence interval and results are given in Table 2.

Based on uncertainty values from Table 2 it can be concluded that relative uncertainties are generally similar on two concentration levels with tendency for slightly higher uncertainty on higher concentration level $(10 \times$ LOQ). Noticeable exceptions are pyraclostrobin and azoxystrobin since relative expanded uncertainties $U(Y) r$ for them are lower on higher concentration level (could be related to high LOQ values). Chlorothalonil (on two concentration levels), together with kresoxim-methyl, lambda-cyhalothrin and benalaxyl (only on higher concentration level) have relative expended uncertainties around or higher than $50 \%$, while it was found for the rest of the pesticides that relative expended uncertainties are lower than $50 \%$, that is, below acceptable value.

\section{Matrix Effect}

The matrix effect is still one of the major problems in pesticides analysis. Although determination techniques like liquid and gas chromatography coupled with tandem mass spectrometry are powerful tools for identification and quantification of pesticides residues, in many cases they are not sufficient for reducing influence of matrix. Source of errors can be both, matrix and analyte dependent. Active

Table 2. Measurement uncertainty at two concentration levels $(2 \times \mathrm{LOQ}$ and $10 \times \mathrm{LOQ})$ for 25 pesticides estimated from validation data over five days.

\begin{tabular}{|c|c|c|c|c|c|c|c|c|c|c|c|c|}
\hline Compound & $\begin{array}{c}2 \times \mathrm{LOQ} / \\
\mu \mathrm{g} \mathrm{L}^{-1}\end{array}$ & $\begin{array}{c}s_{W L} / \\
\mu g L^{-1} \\
\end{array}$ & $\begin{array}{l}u(\delta) / \\
\mu g L^{-1}\end{array}$ & $\begin{array}{l}u(Y) / \\
\mu g L^{-1}\end{array}$ & $\begin{array}{l}U(Y) / \\
\mu g L^{-1} \\
\end{array}$ & $U(Y) r / \%$ & $\begin{array}{c}10 \times \mathrm{LOQ} / \\
\mu \mathrm{g} \mathrm{L}^{-1}\end{array}$ & $\begin{array}{c}s_{W L} / \\
\mu g L^{-1}\end{array}$ & $\begin{array}{l}u(\delta) / \\
\mu g \mathrm{~L}^{-1}\end{array}$ & $\begin{array}{l}u(Y) / \\
\mu g^{-1}\end{array}$ & $\begin{array}{l}U(Y) / \\
\mu g L^{-1} \\
\end{array}$ & $\begin{array}{c}U(Y) r / \\
\%\end{array}$ \\
\hline Alpha cypermethrin & 10.12 & 1.016 & 0.38 & 1.085 & 2.169 & $21 \%$ & 50.6 & 8.847 & 3.679 & 9.582 & 19.163 & $38 \%$ \\
\hline Azoxystrobin & 407.59 & 55.697 & 22.199 & 59.958 & 119.916 & $29 \%$ & 2499.5 & 177.739 & 50.543 & 184.786 & 369.572 & $15 \%$ \\
\hline Benalaxyl & 0.5 & 0.059 & 0.027 & 0.065 & 0.129 & $26 \%$ & 2.51 & 0.889 & 0.276 & 0.931 & 1.862 & $74 \%$ \\
\hline Boscalid & 101.4 & 7.86 & 2.335 & 8.2 & 16.399 & $16 \%$ & 405.59 & 36.381 & 13.342 & 38.75 & 77.499 & $19 \%$ \\
\hline Captan & 102.09 & 11.041 & 4.534 & 11.935 & 23.87 & $23 \%$ & 408.36 & 55.622 & 23.627 & 60.432 & 120.863 & $30 \%$ \\
\hline Chlorothalonil & 24.83 & 6.477 & 2.247 & 6.856 & 13.712 & $55 \%$ & 99.3 & 44.229 & 15.475 & 46.859 & 93.717 & $94 \%$ \\
\hline Deltamethrin & 101.09 & 8.307 & 3.329 & 8.949 & 17.898 & $18 \%$ & 404.38 & 64.219 & 26.611 & 69.514 & 139.028 & $34 \%$ \\
\hline Fludioxonil & 409.86 & 47.48 & 18.98 & 51.134 & 102.267 & $25 \%$ & 2486.88 & 428.564 & 179.09 & 464.479 & 928.958 & $37 \%$ \\
\hline Fluopicolide & 9.7 & 1.372 & 0.56 & 1.482 & 2.964 & $31 \%$ & 48.51 & 5.874 & 1.884 & 6.169 & 12.337 & $25 \%$ \\
\hline Fluquinconazole & 10.05 & 1.155 & 0.486 & 1.253 & 2.506 & $25 \%$ & 50.24 & 3.556 & 0.792 & 3.643 & 7.286 & $15 \%$ \\
\hline Flusilazole & 9.65 & 1.166 & 0.473 & 1.259 & 2.518 & $26 \%$ & 48.27 & 8.344 & 2.911 & 8.837 & 17.674 & $37 \%$ \\
\hline Iprodione & 2.54 & 0.391 & 0.166 & 0.425 & 0.849 & $33 \%$ & 10.18 & 2.261 & 0.802 & 2.399 & 4.799 & $47 \%$ \\
\hline Kresoxim methyl & 9.71 & 1.411 & 0.591 & 1.53 & 3.06 & $32 \%$ & 48.54 & 12.162 & 4.718 & 13.045 & 26.091 & $54 \%$ \\
\hline Lambda cyhalothrin & 9.93 & 1.043 & 0.43 & 1.128 & 2.257 & $23 \%$ & 49.63 & 11.764 & 4.383 & 12.554 & 25.109 & $51 \%$ \\
\hline Metalaxyl & 25.35 & 3.617 & 1.443 & 3.894 & 7.788 & $31 \%$ & 101.4 & 20.293 & 8.123 & 21.858 & 43.717 & $43 \%$ \\
\hline Myclobutanil & 25.22 & 2.435 & 0.743 & 2.546 & 5.092 & $20 \%$ & 100.89 & 17.871 & 7.619 & 19.427 & 38.855 & $39 \%$ \\
\hline Propiconazole & 9.9 & 1.034 & 0.394 & 1.106 & 2.212 & $22 \%$ & 49.48 & 7.852 & 3.186 & 8.474 & 16.948 & $34 \%$ \\
\hline Pyraclostrobin & 403.6 & 47.197 & 17.562 & 50.359 & 100.717 & $25 \%$ & 2497.5 & 199.451 & 64.763 & 209.702 & 419.405 & $17 \%$ \\
\hline Pyrimethanil & 10.2 & 1.626 & 0.664 & 1.756 & 3.512 & $34 \%$ & 50.99 & 6.075 & 2.224 & 6.469 & 12.938 & $25 \%$ \\
\hline Spirodiclofen & 99.12 & 9.199 & 3.703 & 9.917 & 19.833 & $20 \%$ & 396.47 & 25.965 & 7.716 & 27.087 & 54.175 & $14 \%$ \\
\hline Spiroxamine & 99 & 8.861 & 2.291 & 9.152 & 18.305 & $18 \%$ & 396 & 76.292 & 33.358 & 83.266 & 166.532 & $42 \%$ \\
\hline Tebuconazole & 98.01 & 14.712 & 6.054 & 15.909 & 31.817 & $32 \%$ & 392.03 & 42.262 & 16.372 & 45.322 & 90.645 & $23 \%$ \\
\hline Thiamethoxam & 100.47 & 12.773 & 4.833 & 13.656 & 27.313 & $27 \%$ & 401.88 & 48.439 & 19.626 & 52.264 & 104.528 & $26 \%$ \\
\hline Trifloxystrobin & 10.07 & 1.387 & 0.534 & 1.486 & 2.973 & $30 \%$ & 50.34 & 5.513 & 2.26 & 5.958 & 11.916 & $24 \%$ \\
\hline Zoxamide & 103.09 & 8.800 & 3.909 & 9.629 & 19.257 & $19 \%$ & 412.34 & 40.747 & 15.065 & 43.443 & 86.886 & $21 \%$ \\
\hline
\end{tabular}


sites in GC systems (injector, column, detector) are often responsible for enhancement of signal causing degradation or retention of analytes. ${ }^{[18]}$ These active sites are filled only with analytes in the case of pesticides solvent solutions. However, in matrix samples these sites are filled mainly with matrix component which results in signal enhancement and/or suppression. There are several approaches aiming at reduction of matrix influence. The optimization of sample preparation is the most efficient way for reducing the amount of matrix components that are often coextracted together with analyte. The use of analyte protectants or isotopically labeled internal standards is a good choice, but very expensive and as such not applicable for routine analysis. The standard addition method is option for precise reduction of matrix components but it is time consuming and as such not practical for multiresidue analysis. Matrix-matched calibration is the most common approach due to its simplicity.

The measure of matrix effect can be estimated from signal responses in matrix and signal responses in solvent (for identical concentration of pesticide). ${ }^{[12,19]}$ Equivalent measure of matrix effect $(M E)$ can be deduced from the ratio of the slopes of the pesticide calibration curves in matrix and in solvent ${ }^{[5,21]}$. Constructed in this way, measure $M E$ provides information on matrix effect in the whole linearity range. Matrix effect has been estimated using the latter approach, calculating $M E$ using the formula: $M E(\%)=\left(1-S_{m} /\right.$ $\left.S_{s}\right) \times 100$, where $S_{m}$ is the slope of the calibration curve in matrix while $S_{s}$ is the slope of the calibration curve in pure solvent for same pesticide. Results of matrix effect estimation are presented in Table 3. Impact of the matrix was proclaimed as low for values of $M E$ in range $-20 \%<M E<$

Table 3. Physico-chemical properties of 25 pesticides, matrix effect (ME) and extraction efficiency (EE\%).

\begin{tabular}{|c|c|c|c|c|c|c|}
\hline Compound & molecular formula & $\begin{array}{c}\text { molecular weight / } \\
\mathrm{g} \mathrm{mol}^{-1}\end{array}$ & $\begin{array}{c}\text { solubility in water / } \\
\mathrm{mg} \mathrm{L}^{-1}\end{array}$ & $K_{\text {ow }}\left(20^{\circ} \mathrm{C}\right)$ & $E E / \%$ & ME effect \\
\hline Alpha cypermethrin & $\mathrm{C}_{22} \mathrm{H}_{19} \mathrm{Cl}_{2} \mathrm{NO}_{3}$ & 416.3 & 0.004 & 6.6 & 60 & medium suppression \\
\hline Azoxystrobin & $\mathrm{C}_{22} \mathrm{H}_{17} \mathrm{~N}_{3} \mathrm{O}_{5}$ & 403.4 & 6 & 2.5 & 61 & medium enhancement \\
\hline Benalaxyl & $\mathrm{C}_{20} \mathrm{H}_{23} \mathrm{NO}_{3}$ & 325.4 & 28.6 & 3.5 & 64 & low effect \\
\hline Boscalid & $\mathrm{C}_{18} \mathrm{H}_{12} \mathrm{Cl}_{2} \mathrm{~N}_{2} \mathrm{O}$ & 343.2 & 4.64 & 2.9 & 67 & high suppression \\
\hline Captan & $\mathrm{C}_{9} \mathrm{H}_{8} \mathrm{Cl}_{3} \mathrm{NO}_{2} \mathrm{~S}$ & 300.6 & 3.3 & 2.8 & 103 & high suppression \\
\hline Chlorothalonil & $\mathrm{C}_{8} \mathrm{Cl}_{4} \mathrm{~N}_{2}$ & 265.9 & 0.81 & 2.9 & 191 & high suppression \\
\hline Deltamethrin & $\mathrm{C}_{22} \mathrm{H}_{19} \mathrm{Br}_{2} \mathrm{NO}_{3}$ & 505.2 & 0.0002 & 4.6 & 58 & medium suppression \\
\hline Fludioxonil & $\mathrm{C}_{12} \mathrm{H}_{6} \mathrm{~F}_{2} \mathrm{~N}_{2} \mathrm{O}_{2}$ & 248.2 & 1.8 & 4.1 & 72 & medium suppression \\
\hline Fluopicolide & $\mathrm{C}_{14} \mathrm{H}_{8} \mathrm{Cl}_{3} \mathrm{~F}_{3} \mathrm{~N}_{2} \mathrm{O}$ & 383.59 & 2.8 & 3.3 & 87 & low effect \\
\hline Fluquinconazole & $\mathrm{C}_{16} \mathrm{H}_{8} \mathrm{Cl}_{2} \mathrm{FN}_{5} \mathrm{O}$ & 376.2 & 1 & 3.2 & 73 & low effect \\
\hline Flusilazole & $\mathrm{C}_{16} \mathrm{H}_{15} \mathrm{~F}_{2} \mathrm{~N}_{3} \mathrm{Si}$ & 315.4 & 42 & 3.9 & 87 & low effect \\
\hline Iprodione & $\mathrm{C}_{13} \mathrm{H}_{13} \mathrm{Cl}_{2} \mathrm{~N}_{3} \mathrm{O}_{3}$ & 330.2 & 13 & 3.0 & 56 & medium suppression \\
\hline Kresoxim methyl & $\mathrm{C}_{18} \mathrm{H}_{19} \mathrm{NO}_{4}$ & 313.8 & 2 & 3.4 & 92 & low effect \\
\hline Lambda cyhalothrin & $\mathrm{C}_{22} \mathrm{H}_{19} \mathrm{ClF}_{3} \mathrm{NO}_{3}$ & 449.9 & 0.005 & 7.0 & 63 & medium suppression \\
\hline Metalaxyl & $\mathrm{C}_{15} \mathrm{H}_{21} \mathrm{NO}_{4}$ & 279.3 & 8.4 & 1.7 & 85 & low effect \\
\hline Myclobutanil & $\mathrm{C}_{15} \mathrm{H}_{17} \mathrm{ClN}_{4}$ & 288.8 & 142 & 2.9 & 111 & low effect \\
\hline Propiconazole & $\mathrm{C}_{15} \mathrm{H}_{17} \mathrm{Cl}_{2} \mathrm{~N}_{3} \mathrm{O}_{2}$ & 342.2 & 100 & 3.7 & 88 & low effect \\
\hline Pyraclostrobin & $\mathrm{C}_{19} \mathrm{H}_{18} \mathrm{ClN}_{3} \mathrm{O}_{4}$ & 387.8 & 1.9 & 4.0 & 41 & medium enhancement \\
\hline Pyrimethanil & $\mathrm{C}_{12} \mathrm{H}_{13} \mathrm{~N}_{3}$ & 199.3 & 0.12 & 2.8 & 66 & low effect \\
\hline Spirodiclofen & $\mathrm{C}_{21} \mathrm{H}_{24} \mathrm{Cl}_{2} \mathrm{O}_{4}$ & 411.3 & 0.05 & 5.8 & 64 & high suppression \\
\hline Spiroxamine & $\mathrm{C}_{18} \mathrm{H}_{35} \mathrm{NO}_{2}$ & 297.5 & 470 & 2.8 & 83 & low effect \\
\hline Tebuconazole & $\mathrm{C}_{16} \mathrm{H}_{22} \mathrm{CIN}_{3} \mathrm{O}$ & 307.8 & 32 & 3.7 & 86 & medium enhancement \\
\hline Thiamethoxam & $\mathrm{C}_{8} \mathrm{H}_{10} \mathrm{ClN}_{5} \mathrm{O}_{3} \mathrm{~S}$ & 291.7 & 4100 & -0.1 & 68 & medium enhancement \\
\hline Trifloxystrobin & $\mathrm{C}_{20} \mathrm{H}_{19} \mathrm{~F}_{3} \mathrm{~N}_{2} \mathrm{O}_{4}$ & 408.4 & 0.61 & 4.5 & 105 & low effect \\
\hline Zoxamide & $\mathrm{C}_{14} \mathrm{H}_{16} \mathrm{Cl}_{3} \mathrm{NO}_{2}$ & 336.7 & 0.681 & 3.8 & 67 & high suppression \\
\hline
\end{tabular}

$\mathrm{K}_{\mathrm{ow}}$ - distribution coefficient between $\mathrm{n}$-octanol and water, $\mathrm{EE}$ - extraction efficiency, ME - matrix effect. 


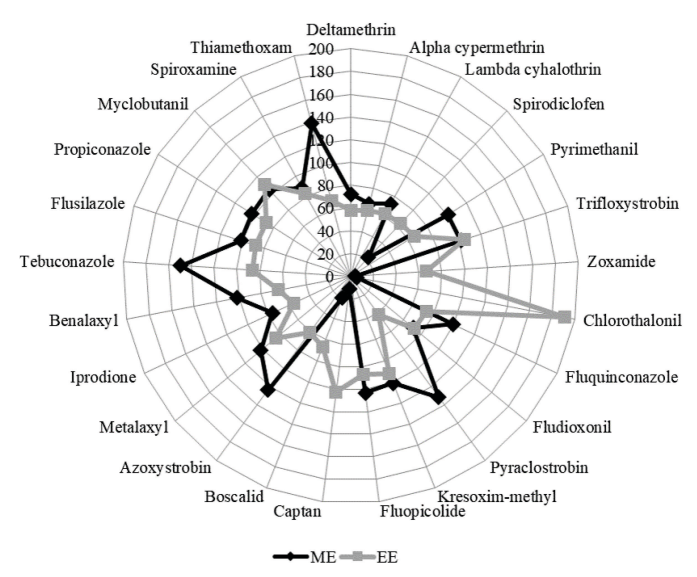

Figure 2. Matrix effect (ME) and extraction efficiency (EE) sorted by pesticides solubility in water.

$20 \%$, medium suppression for $-50 \%<M E<-20 \%$, or high suppression for $M E<-50 \%$. Positive values indicate analytical signal enhancement therefore values of $M E$ in range 20 $\%<M E<50 \%$ were considered as medium enhancement while $50 \%<M E$ was proclaimed as high enhancement. Based on this criteria out of 25 pesticides 11 of them demonstrate low matrix effect, 4 medium suppression, 5 medium enhancement and 5 high enhancement. Since matrix effect was established on $40 \%$ of the pesticides of interest, use of matrix-matched calibration was justified.

Extraction efficiency $(E E)$ of the procedure was calculated at two concentration levels $(2 \times \mathrm{LOQ}$ and $10 \times \mathrm{LOQ})$ as: $E E(\%)=\left[\left(A_{s s}-A_{n s}\right) /\left(A_{s e}-A_{n e}\right)\right] \times 100$, where $A_{s s}$ is signal of wine sample spiked before extraction and $A_{\mathrm{ns}}$ is signal of non-spiked wine sample, $A_{\text {se }}$ is signal of wine sample spiked after extraction and $A_{n e}$ is signal of the non-spiked aliquot of the same wine sample. The average of two concentration levels for $E E$ values are presented in Table 3. Extraction efficiency of proposed methodology was higher on $10 \times \mathrm{LOQ}$ concentration level for $68 \%$ of the pesticides. In $76 \%$ of the cases (pesticides), presence of matrix effect coincides with more significant extraction efficiency break from the norm which is considered to be around $100 \%$. This is another indicator of already assumed strong influence of the matrix.

In Figure 2 pesticides are ordered according to their solubility in water (Table 3 ) in a clockwise direction in increasing order starting with deltamethrin $\left(0.0002 \mathrm{mg} \mathrm{L}^{-1}\right)$, for each pesticide average $E E$ value and modified $M E$ value are plotted. $M E$ values for the purpose of demonstration are shifted by a factor of 100 so that $100 \%$ represents low matrix effect and the rest of the criteria are shifted accordingly.

$M E$ are generally low or medium, while $E E$ values are between 60 and $120 \%$, with tendency for higher values of $E E$ and more prominent $M E$ for pesticides with higher solubility. Noticeable exceptions are spirodiclofen, chlorothalonil, pyraclostrobin and boscalid. In case of chlorothalonil high signal suppression found in $M E$ together with extremely high $E E$ could indicate high influence of matrix, not related to the extraction procedure.

\section{Application of the Method}

Developed method was successfully applied to 12 Croatian red wine samples of different variety. The five point matrixmatched calibration solutions (LOQ, $2 \times$ LOQ, $5 \times$ LOQ, $10 \times$ LOQ and $25 \times$ LOQ) were used for pesticide quantification. As demonstrated in Table 4, 10 pesticides were detected

Table 2. Concentration of target pesticides in 12 red wine samples (given as mean together with uncertainty in $\mu \mathrm{g} \mathrm{L}^{-1}$ ).

\begin{tabular}{|c|c|c|c|c|c|c|c|c|c|c|c|}
\hline $\begin{array}{l}\text { Wine } \\
\text { code }\end{array}$ & $\begin{array}{l}\text { Type of } \\
\text { grape }\end{array}$ & Pyrimethanil & Metalaxyl & Benalaxyl & $\begin{array}{c}\text { Trifloxystro- } \\
\text { bin }\end{array}$ & $\begin{array}{l}\text { Tebuco- } \\
\text { nazole }\end{array}$ & $\begin{array}{l}\text { Cyhalothrin } \\
\text { lambda }\end{array}$ & $\begin{array}{l}\text { Cypermethrin } \\
\text { alpha }\end{array}$ & $\begin{array}{c}\text { Fluquinco- } \\
\text { nazole }\end{array}$ & $\begin{array}{l}\text { Myclobu- } \\
\text { tanil }\end{array}$ & $\begin{array}{l}\text { Flusila- } \\
\text { zole }\end{array}$ \\
\hline 45 & Frankovka & $61.1 \pm 0.2$ & $27 \pm 0.3$ & n.d. & n.d. & n.d. & $6.0 \pm 0.2$ & n.d. & n.d. & n.d. & n.d. \\
\hline 46 & Frankovka & $16.9 \pm 0.3$ & $24.1 \pm 0.3$ & $1.6 \pm 0.5$ & n.d. & n.d. & $6.7 \pm 0.2$ & n.d. & n.d. & n.d. & n.d. \\
\hline 47 & Frankovka & $17.3 \pm 0.3$ & $13.3 \pm 0.3$ & $19 \pm 5$ & n.d. & $79.8 \pm 0.3$ & $5.9 \pm 0.2$ & n.d. & n.d. & n.d. & n.d. \\
\hline 48 & Frankovka & $61.8 \pm 0.2$ & $15.6 \pm 0.3$ & $1.9 \pm 0.6$ & n.d. & n.d. & $6.1 \pm 0.2$ & n.d. & n.d. & n.d. & n.d. \\
\hline 49 & Frankovka & $21.8 \pm 0.3$ & $17.3 \pm 0.3$ & $1.5 \pm 0.5$ & n.d. & n.d. & $6.0 \pm 0.2$ & $10.4 \pm 0.2$ & n.d. & n.d. & n.d. \\
\hline 50 & Frankovka & $22.1 \pm 0.3$ & 17. \pm 0.3 & $2.3 \pm 0.7$ & n.d. & n.d. & $6.1 \pm 0.2$ & n.d. & n.d. & n.d. & n.d. \\
\hline 51 & Frankovka & $19.5 \pm 0.3$ & $18.2 \pm 0.3$ & $1.7 \pm 0.5$ & n.d. & n.d. & $6.2 \pm 0.2$ & $6.3 \pm 0.2$ & n.d. & n.d. & n.d. \\
\hline 52 & Frankovka & $17.4 \pm 0.3$ & $15.9 \pm 0.3$ & $1.4 \pm 0.5$ & $5.7 \pm 0.3$ & n.d. & $6.0 \pm 0.2$ & $6.3 \pm 0.2$ & $7.3 \pm 0.3$ & $20.1 \pm 0.2$ & $8.7 \pm 0.3$ \\
\hline 53 & Zweigelt & $9.5 \pm 0.4$ & $19.0 \pm 0.3$ & $0.4 \pm 0.2$ & n.d. & n.d. & $6.6 \pm 0.2$ & n.d. & n.d. & n.d. & n.d. \\
\hline 54 & Zweigelt & n.d. & $19.2 \pm 0.3$ & $0.6 \pm 0.3$ & $10.6 \pm 0.3$ & n.d. & $15.8 \pm 0.3$ & $22.1 \pm 0.3$ & n.d. & n.d. & n.d. \\
\hline 55 & Plavac & n.d. & $14.3 \pm 0.3$ & $0.9 \pm 0.4$ & $5.8 \pm 0.3$ & n.d. & n.d. & $6.0 \pm 0.2$ & n.d. & n.d. & n.d. \\
\hline 56 & Pinot noir & n.d. & $28.9 \pm 0.3$ & $1.2 \pm 0.4$ & $5.8 \pm 0.3$ & n.d. & n.d. & $6.4 \pm 0.2$ & n.d. & n.d. & n.d. \\
\hline
\end{tabular}


above LOQ value. Pyrimethanil and metalaxyl were detected in concentrations above $10 \mu \mathrm{g} \mathrm{L}^{-1}$. Metalaxyl, lambda-cyhalothrin, pyrimethanil, benalaxyl and alphacypermethrin were most frequently found in red wines. At least 3 pesticides were found in each red wine.

Obtained results are consistent with findings of other authors. For example, Fontana ${ }^{[12]}$ reported significant levels of metalaxyl, myclobutanil, benalaxyl and tebuconazole, while Economou ${ }^{[5]}$ detected metalaxyl and pyrimethanil. Globally, the presence of these pesticides was confirmed in many European wines. ${ }^{[10,20,21]}$ According to the recent study, a $30 \%$ of overall analysed pesticides in grapes are transferred to wines. ${ }^{[22]}$ Overall results indicate significant concentrations of pesticides residues in wine with raising concern for consumer intake.

\section{CONCLUSION}

Developed GC-MS methodology provides novel, selective and accurate approach for determination of 25 pesticide residues in red wine. At the same time, major findings of this research significantly expand current knowledge about the QuEChERS theory. Originally developed for vegetables products, QuEChERS method was proved to be inadequate for analysis of selected pesticides in red wine producing recoveries under $20 \%$. With the major goal of modifying the QuEChERS, as very simple extraction technique, and making it suitable for red wine analysis, a new multiresidue method has been developed and successfully applied on complex matrix of red wine. Limits of detection and quantification of new method were satisfactory $\left(0.01-250 \mu \mathrm{g} \mathrm{L}^{-1}\right)$ and well below maximum residue levels prescribed by European Union. Presence of matrix effect has been investigated and confirmed. Matrix-matched calibration was used for quantification of pesticides due to established matrix effect. Quality of the method has been investigated and confirmed during the validation procedure. Satisfactory recoveries (70-120\%) and expanded relative uncertainties (<50\%) were found for $80 \%$ and $90 \%$ of the pesticides respectively. The proposed analytical procedure has been applied to red wine samples of different origin. Results indicated significant levels of wine contamination what is in accordance with recent studies conducted in Europe.

Acknowledgment. This study was financially supported by the Croatian Centre for Agriculture, Food and Rural Affairs, Institute for Plant Protection. The authors would like to thank Marko Karoglan for donation of red wine samples.

Author Contribution Statement. OP designed experiments, performed chemical analyses and wrote manuscript; AV performed biological assays; IC collected plant materials and assisted during the experiments.
Conflict of interest. Authors declare that they have no conflict of interests.

Ethical approval. This article does not contain any studies with human participants or animals performed by any of the authors.

\section{REFERENCES}

[1] A. Balinova, R. Mladenova, D. Shtereva, J. Chromatogr. A. 2007, 1150, 136-144.

https://doi.org/10.1016/j.chroma.2007.02.002

[2] S. J. Lehotay, K. Mastovská, A.R. Lightfield, J AOAC Int. 2005; 88, 615-629.

[3] A. Wilkowska, M. Biziuk, Food Chem. 2011, 125, 803-812.

https://doi.org/10.1016/j.foodchem.2010.09.094

[4] C. Lesueur, P. Knittl, M. Gartner, A. Mentler, M. Fuerhacker. Food Control. 2008, 19, 906-914. https://doi.org/10.1016/j.foodcont.2007.09.002

[5] J.Y. Park, J. H. Choi, A.M. Abd El-Aty, Food Chem. 2011, 128, 241-253. https://doi.org/10.1016/j.foodchem.2011.02.065

[6] K. Maštovská, S.J. Lehotay, J Chromatogr A. 2004, 1040, 259-272.

https://doi.org/10.1016/j.chroma.2004.04.017

[7] S. N. Sinha, K. Vasudev, M. Vishnu Vardhana Rao, Food Chem. 2012, 132, 1574-1584.

https://doi.org/10.1016/j.foodchem.2011.11.102

[8] J. Jiménez, J. Bernal, M. del Nozal, L. Toribio, E. Arias, J Chromatogr A. 2001, 919, 147-156.

https://doi.org/10.1016/S0021-9673(01)00632-X

[9] J.W. Wong, M.G. Webster, C. A. Halverson, M. J. Hengel, K. K. Ngim, S.E. Ebeler. J. Agric. Food Chem. 2003, 51, 1148-1161.

https://doi.org/10.1021/jf0209995

[10] I. Carpinteiro, M. Ramil, I. Rodríguez, R. Cela, J. Chromatogr A. 2010, 1217, 7484-7492. https://doi.org/10.1016/j.chroma.2010.09.080

[11] A. Economou, H. Botitsi, S. Antoniou, D. Tsipi, J. Chromatogr A. 2009, 1216, 5856-5867. https://doi.org/10.1016/j.chroma.2009.06.031

[12] A. R. Fontana, I. Rodríguez, M. Ramil, J. C. Altamirano, R. Cela, J. Chromatogr A. 2011, 1218, 2165-2175. https://doi.org/10.1016/j.chroma.2011.02.025

[13] X. Wang, T. Michael, LCGC Eur. 2013 2, 165-177

[14] M. Anastassiades, S. J. Lehotay, D. Stajnbaher, F. J. Schenck, J AOAC Int. 2003, 86, 412-431.

[15] M. Anastassiades, K. Maštovská, S. J. Lehotay, J. Chromatogr A. 2003, 1015, 163-184. https://doi.org/10.1016/S0021-9673(03)01208-1.

[16] R.E. Majors. LCGC Asia Pacific Vol 11, Issue 1. 2008. 
[17] European Commission, SANCO. SANCO/12571/2013. 2013:42.

[18] H. Kwon, S. J. Lehotay, L. Geis-Asteggiante J Chromatogr. A. 2012, 1270, 235-245. https://doi.org/10.1016/j.chroma.2012.10.059

[19] B. K. Matuszewski, M. L. Constanzer, C. M. ChavezEng, Anal Chem. 2003, 75, 3019-3030. https://doi.org/10.1021/ac020361s

[20] E. R. Trösken, N. Bittner, W. Völkel J Chromatogr A.
2005, 1083, 113-119.

https://doi.org/10.1016/j.chroma.2005.06.020

[21] R. Montes, I. Rodríguez, M. Ramil, E. Rubí, R. Cela. J Chromatogr A. 2009, 216, 5459-5466. https://doi.org/10.1016/j.chroma.2009.05.048

[22] Pesticide Action Network Europe. Message in a Bottle. Briefing.

[23] He Y, Liu Y-H. Chromatographia 2007, 65, 581-590. https://doi.org/10.1365/s10337-007-0198-6 